\title{
Is there a case for single sex wards?
}

\author{
Claire Henderson and Adrianne Reveley
}

"Most in-patient units ... provide mixed wards as a matter of policy. However ... women have begun to insist that they would prefer single gender wards. . . the Commission believes that the whole policy regarding mixed wards may have to be reviewed in due course." (Mental Health Act Commission, 1993)

\section{Why did wards go mixed in the first place?}

In the 1960s, when the old long-stay wards began to empty, the prevailing ideology was that mixed gender institutions were healthier places than single sex ones. Mixed sex education was increasing in schools and even in previously male Oxbridge colleges.

Within psychiatry, mixed sex in-patient units were introduced by the therapeutic community movement, developed primarily by Maxwell Jones (e.g. Jones, 1982). Writing about the first year of a therapeutic community at Dingleton Hospital in 1963. Jones appears to view staff concerns that relaxing rules would lead to sexual licence as a hurdle to be taken in the process of gradually granting patients more freedom, which they would use responsibly:

"The issue of permissiveness and licence created problems for many months and . . . was part of an evolutionary process ... We heard reports from the male admission ward that patients were getting the idea that they could do what they liked sexually and that Dr Jones was sanctioning all kinds of freedom."

This was clearly not the intention at Dingleton, but in some communities it was felt vital "to foster a permissive environment which will encourage the acting out of impulses and assimilate the consequences" (Rapoport, 1960). This was believed to be highly therapeutic:

"not all sexual activities and experimentation is approved, but individual experimentation may be encouraged for some therapeutic problems and needs."

This attitude may now seem more than a shade utopian, but it must be remembered that it was based on very different ideas about the causes of mental disorder (including Freudian theory and the effects of institutionalisation) than those with which we now view the current inpatient population. It was also part of an attempt to normalise the lives of patients on long-stay wards, who formed a fairly stable population at the time. However, in common with many health service reforms, mixed sex inpatient wards were poorly researched before being put into practice.

\section{A changing pattern of care}

In the Special Health Authority, mixed sex wards were originally seen as normal, therapeutic and progresstve (Batcup, 1994). However, deinstitutionalisation has resulted in a more acutely unwell in-patient population staying for briefer periods. There is much more disturbed and violent behaviour (Patrick et al, 1989), and encouragement of 'acting out' behaviour would seem ludicrously dangerous.

By the time there was a wholesale move to community care, mixed sex wards were taken for granted, and were likely to have been necessary anyway on the basis of an economy of scale; bed numbers shrank, large asylums were replaced with new psychiatric units within general hospitals, in-patient stays diminished, and sectorisation replaced gender as the main determinant of a patient's ward allocation.

Thus reforms directed towards the normalisation of long-term residents of large institutions were used to legitimise the maximisation of bed occupancy by a more acute patient population, in a much less stable in-patient community.

\section{How are mixed sex wards seen by the patients?}

If mixed sex nursing is potentially unsuitable for an acutely disturbed population, is it still welcomed by the existing long-stay population? While no single patient satisfaction study has sought to compare the views of patients on 
acute versus longer-stay wards, a comparison of the result of two recent studies can be made.

A study of 71 patients living on single sex continuing care wards (Hingley \& Goodwin, 1994) showed a complex picture of preferences. While many patients made a distinction between living and socialising with the opposite sex, this was much more so for men than women: $33 \%$ of men said they preferred mixed sex living compared to $82 \%$ who preferred both sexes to be present at hospital social events: $48 \%$ of women preferred mixed sex accommodation (a trend when compared to men) but only $63 \%$ wanted to mix with men at socials. A content analysis of patients' comments revealed a high level of ambivalence about mixed sex living.

In contrast, Myers et al (1990) found that acute ward patients of similar age to Hingley and Goodwin's sample showed a much greater preference for single sex accommodation. Being female and being aged over 40 were associated with same sex preference, as was being on a same sex ward. This study has the advantage of including patients on single and mixed wards; the apparent preference of patients for the ward type they are already on may reflect their putting up with where they are, or a general feeling of satisfaction with the ward which influences preference. Further, it is difficult to express a preference if one has only experienced one or the other type of ward (Thomas \& Batcup, 1994). Future studies of patient satisfaction should take patients' previous admission experiences into account.

\section{What are the reasons for patient choice?}

Why do patients prefer single or mixed sex accommodation? Thomas et al (1992) asked the preferences of 150 patients admitted to acute, speciality and elderly wards, all of which were mixed: $24 \%$ had no preference, while $57 \%$ preferred mixed sex wards; their reasons included a more balanced atmosphere, the fact that this reflected the outside world, and that it was good to mix with the opposite sex. For some men this included the possibility of finding sexual partners and forming relationships; men also said women were less violent and had a calming effect on the ward.

Of the $28(19 \%)$ of responders who preferred single sex accommodation, $19(68 \%)$ were women, and formed $27 \%$ of all female patients in the study. They said they would have felt safer on a women-only unit which would be less violent and provide more privacy. Some felt nervous in male company, others had been harassed by men who had entered their rooms.

\section{Are women vulnerable on mired sex wards?}

The assumption that women will be safer on a single sex ward is based on the fact that in the community, most violent crime is committed by young men. However, the literature on violence in psychiatric hospitals (e.g. Noble \& Rodger, 1989) gives a very different picture. Noble \& Rodger found that although the three most serious assaults were perpetrated by men, men and women had equal rates of other episodes of violence, and there was considerable spread in the age range. Similarly, Miller et al (1993) found that gender and age consistently failed to predict assaultiveness, which was much better predicted by diagnosis.

Although the violence literature provides useful demographic data on the perpetrators, it unfortunately tends to categorise victims as staff versus patients, and not by gender. Nevertheless, the differences it shows between the general and the psychiatric populations serves to warn against allowing current concerns about all women's safety (such as marital and date rape, sexual harassment at work and domestic violence) to dictate hospital policy on female patients. There is no evidence that dividing wards into male and female areas, or even resegregating wards, will guarantee safety. Violence by women against women is by no means unheard of on psychiatric wards.

However, occurrences of sexual harassment, assault and rape of female by male patients on mixed psychiatric wards have been discussed in nursing and social work journals over the last few years (e.g. Feinmann, 1988; Cohen, 1992). In a section discussing safety, MIND's (1992) policy on Women and Mental Health claims that: "For many women, mental health services at best do not feel safe and at worst can be physically and emotionally damaging." The document states that "the choice of women-only space needs to be given to all women, including those in long term care."

Such recommendations raise many questions to be addressed if a move back to single sex wards is to avoid being driven only by ideology, repeating the ill thought out shift to mixed wards. Do women on single sex wards feel safer than those on mixed sex wards, and what is the evidence that they are indeed safer? If they are, and assuming that feeling and being safe improves clinical outcome in some measurable way, could outcomes for women on the different ward types be compared? This would necessitate randomisation to each ward type; given the need for informed consent, such a trial could involve only women who did not express a preference on admission. In any case, this issue should be considered at the level of therapeutic benefit as well as patient satisfaction and consumer choice. 
And what about men? Would they appreciate the same choice, and would they benefit from it? Would some patients, male and female, benefit more from one type of ward than another, and are they the same groups as those who express a preference for this type?

Such questions suggest that any review of the policy of mixed sex wards by the Mental Health Act Commission should look carefully at assumptions regarding safety, normalisation and choice. Regarding choice, some indirect evidence exists that women who could be assumed to benefit from a single sex ward may indeed choose one. A comparison of a women only versus two traditional residential drug treatment centres (Copeland \& Hall, 1992) showed that those attending the former were more likely to report sexual abuse in childhood, a factor highly likely to be related to concerns about safety.

Regarding normalisation, at first sight the importance of mixing the sexes to normalise the social environment seems more important for longer-stay wards. However, cultural variation in the level of social interaction between the sexes needs to be borne in mind with respect to ethnic and religlous minorities; for many Moslem and orthodox Jewish people, the close proximity of unrelated members of the opposite gender is an unusual and uncomfortable situation.

While we would not recommend a wholesale shift to single sex psychiatric wards throughout the National Health Service, we are advocating that women should be able to choose this aspect of their in-patient environment. Too often we find that choices for psychiatric patients are severely restricted; geography may dictate the consultant while cost may influence treatment and housing options. Whatever the statistics, if some women some of the time feel safer in a single sex environment there is undoubtedly a therapeutic benefit in providing this. Indeed, their vulnerability may necessitate a single sex ward as the only humane environment for treatment.

\section{References}

BATCUP, D. (1994) Mixed sex wards: recognising and responding to gender issues in mental health settings and evaluating thetr safety for women. Interim report for the Bethlem and Maudsley NHS Trust. The Maudsley Audit Office.

CoHEN, P. (1992) High-risk mix. Social Work Today, $23,31$.

COPELAND, J. \& HALL, W. (1992) A comparison of women seeking drug and alcohol treatment in a specialist women's and two traditional mixed-set treatment services. British Joumal of Addiction, 87, 1293-1302.

Feinmann, J. (1988) Corridors of fear. Nursing Times, 84, 16-17.

HINGLEY, S. \& GOODWIN, A. (1994) Living with the opposite sex: the views of long stay psychiatric patients. British Joumal of Clinical Psychology. 3, 183-192.

JONES, M. (1982) The Process of Change. London: Routledge and Kegan Paul.

MENTAL HEALTH ACT COMMISSION (1993) Blennial Report 1991-1993.

MinueR, R. J., ZADOLINNYJ, K. \& HAFNER, R. J. (1993) Profiles and predictors of assaultiveness for different psychiatric ward populations. American Joumal of Psychiatry. 150. 1368-1373.

MIND (1992) Women and Mental Health: MIND Policy Paper. London: MIND.

MYERS, D. H., LEAHY, A., SHOEB, H., et al (1990) The patlents' view of life in a psychiatric hospital. Brttlsh Journal of Psychiatry, 166, 853-860.

NOBLE, P. \& RODGER, S. (1989) Vlolence by psychiatric inpatients. British Journal of Psychiatry, 185, 384-390.

PATRICK, M., HigGr, A., Holloway, F., et al (1989) Changes in an inner city psychiatric service following bed losses: a follow-up of the East Lambeth 1986 Survey. Health Trends, 21, 121-123.

RAPOPORT, R. N. (1960) Community as Doctor. London: Tavistock Publications.

THOMAS, B., LANESS, S., VEARNALS, S., et al (1992) Involuntary cohabitees. Nursing Times, 88, 58-60.

- \& BATCUP, D. (1994) Mixing the genders, an ethical dilemma: how nursing theory has dealt with sexuality and gender. Nursing Ethics, 1, 43-51.

Claire Henderson, Senior House Officer in Psychiatry, and *Adrianne Reveley, Consultant Pyschiatrist, National Psychosis Unit, Bethlem Royal Hospital, Monks Orchard Road, Beckenham, Kent BR3 3BL

*Correspondence 